\title{
Produção da subjetividade na Era da Técnica
}

Production of subjectivity in the Era of Technique

Izabella Vidal Coutinho', Leonardo Pinto de Almeida²

\begin{abstract}
Resumo
O presente artigo pretende abordar a questão do pensamento calculante na obra do filósofo Martin Heidegger, pensando como este se faz presente em nosso momento histórico como determinador-produtor de nossas subjetividades. Para tanto, faremos um percurso pelos termos horizonte histórico, Dasein e técnica, identificando as origens buscadas por Heidegger à palavra “cálculo” para embasar o que ele considera o pensamento calculante. Dessa maneira, caminhamos em uma aproximação entre técnica e pensamento calculante, culminando na hipótese de que vivemos na Era da Técnica, justamente por nossa forma de nos relacionarmos com nós mesmos e nosso entorno ocorrer por meio do cálculo.
\end{abstract}

Palavras-chave: Subjetividade. Pensamento Calculante. Heidegger. Era da Técnica.

\begin{abstract}
This article addresses the issue of calculative thinking in the work of the philosopher Martin Heidegger, considering how it is present in our historical moment as determiner-producer of our subjectivities. To do so, we will analyse the terms of historical horizon, Dasein and technique, identifying the sources sought by Heidegger for the word "calculus" to support what he considers calculative thinking. In this way, we advance towards the approximation between technique and calculative thinking, culminating in the hypothesis that we live in the Age of Technique, precisely because our way of relating to ourselves and our surroundings is through calculation.
\end{abstract}

Keywords: Subjectivity. Calculative thinking. Heidegger. Era of Technique.

\footnotetext{
${ }^{1}$ Universidade Federal Fluminense, Niterói, RJ, Brasil. E-mail: izavcoutinho@gmail.com

${ }^{2}$ Universidade Federal Fluminense, Niterói, RJ, Brasil. E-mail: leonardo.p.almeida@gmail.com
} 


\section{Horizonte histórico}

Para pensarmos o presente, devemos ter em mente o conceito de horizonte histórico que Heidegger fundamenta ao longo de suas obras. $\mathrm{O}$ horizonte histórico abrange o momento histórico que nos circunda. É por meio dele que nossas possibilidades de escolha são abertas e que nossos horizontes de sentidos se fundamentam. Ele é o mundo com o qual nos relacionamos como Dasein e nos constituímos como tal. Por isso, não devemos pensar no Dasein separado de seu momento histórico, mas, antes, situá-lo em seu horizonte para que possamos levantar nossas questões.

Faz-se necessário lembrar que o Dasein, já é ser-no-mundo. Ele e mundo são indissociáveis, ou seja, não podemos pensar em um sem considerarmos o outro, sendo, assim, coexistentes. Com isso, compreendemos que ele situa-se em relação ao desvelamento de sentido daquilo que lhe vem ao encontro no mundo. Isso significa que Dasein e mundo são, o tempo inteiro, relação. Cabe ao Dasein dar sentido às coisas que lhe aparecem durante esse relacionar. Por esse motivo, Dasein é mundo - uma vez que "não sendo nenhum tipo de substância anterior a essa abertura compreensiva; ele se reconhece, se identifica, deseja e sonha, a partir de tudo aquilo o que historicamente vem ao seu encontro no mundo" (Novaes \& Rodrigues, 2008, p. 41). Dessa forma, aquilo o que ele é não remontaria a uma interioridade, mas sim a uma exterioridade, ao modo como se articulam as suas experiências de ser-no-mundo-com-os-outros.

No entanto, isso não significa de forma alguma que o Dasein é um produto de seu meio. Se assim o fosse, a dicotomia homem-mundo se manteria efetiva. Homem/Mulher é mundo: isso é o que Heidegger afirma entender no decorrer de seu pensamento desde Ser e Tempo (2008). Outro ponto a ser salientado, uma observação importante a ser feita a respeito do fragmento anterior, é o do Dasein não estar encerrado em um "si mesmo", já que se encontra, desde o início, em um contexto relacional. Isso significa que o Dasein é ser-com: uma vez que está sempre em relação com os outros entes, em coparticipação. Então, o Dasein é ser-no-mundo, sendo assim indissociável com este, e é ser-com, caracterizando-se como um ente em relação. Por isso, ao pensarmos a ideia de horizonte histórico devemos ter em mente que é o mundo com o qual nos relacionamos, coexistimos.

Entretanto, antes de prosseguirmos, é relevante prestarmos atenção para uma sutil diferença, traçada por Heidegger, entre história e historiografia.

Em Meditação (2010b p. 24), encontramos uma nota de rodapé, acrescentada pelo tradutor Casanova, que explica a distinção entre história (Geschichte) e historiografia (Historie). A primeira estaria relacionada às decisões intrínsecas à história do ser, e à constituição dos projetos históricos de mundo. Seriam as decisões do passado que podem ser vistas no presente e que determinarão o futuro. Logo, seriam decisões do passado que nunca se perdem por se fazerem presentes. Já a historiografia, que estaria ligada ao historiográfico, apontaria para uma abordagem lógico-científica dos eventos do passado. Assim, a história seria como o Dasein vivencia suas experiências de realidade, enquanto a historiografia pressupõe uma linearidade de algo em separado do Dasein. 
No pensamento histórico de Heidegger, encontramos duas facetas: por um lado, temos o esforço de pensar o próprio lugar no acontecimento - que estaria do lado da história; e por outro, temos a tentativa de pensar o caráter de tal lugar. É justamente por causa da importância do acontecimento, como conceito diretivo, que a distinção entre história e historiografia torna-se pertinente. Temos assim, então, o problema da técnica - problema esse que é o cerne de nosso discurso acerca do horizonte histórico atual, já que o nosso mundo e o nosso espaço é o da técnica e não podemos deixar de considerar esse espaço como tal.

Heidegger (1957) faz uma observação acerca de seu horizonte histórico e, nela, encontra-se com um termo que estava em bastante uso: Era Atômica. Apesar deste não ser um termo heideggeriano, ele a utilizou com o intuito de se comunicar mais claramente com os que o circundavam. Sobre ela, alegou que seu objetivo era "Salvaguardar a aproveitabilidade da energia atômica e a sua prévia calculabilidade de um modo que esta salvaguarda pelo seu lado provoque permanentemente a ligação de novas seguranças" (Heidegger, 1957, p. 177). Sob esse poder de reivindicação se consolidaria o traço fundamental da moderna exigência humana, que por toda a parte trabalha para a segurança. $\mathrm{O}$ trabalho na salvaguarda da vida também deverá ser permanentemente de novo assegurado.

Sobre o pensamento calculante, afirmaria que é preciso produzir, cada vez mais, cada vez mais rápido. Rapidez significa mais produção, mais produção significa mais armazenamento, e mais armazenamento significa mais garantias. É preciso armazenar, guardar uma reserva para se garantir de que no futuro não venham a surgir necessidades. A necessidade de garantias, de seguranças, só pode ser conseguida se produzida, trazendo a ideia de que é preciso estar seguro sob qualquer hipótese, sob qualquer situação.

A palavra-chave para essa atitude é a information - Heidegger sugere o seu uso na versão inglesa. Ao encontrarmos com essa palavra, tendemos a reduzi-la às vezes somente às mídias mais recorrentes, e deixamos de pensar que ela está inserida em nossas vidas em todos os instantes - até mesmo em conversas informais. Todos os campos do conhecimento necessitam dela para se manter e prosseguir. Dessa maneira, poderíamos pensar que, por meio da informação, a própria linguagem é colocada como disponibilidade no horizonte da com-posição (Gestell) - o que significa ser um modo histórico da experiência do que é a realidade.

No livro Sobre a questão do pensamento (2009), também nos deparamos com a linguagem como sendo disponibilidade. Na parte relativa ao fim da filosofia e a tarefa do pensamento, ele afirma que, de acordo com o caminhar das ciências, em um futuro breve, elas viriam a ser determinadas e dirigidas por uma nova ciência, a qual chamou de cibernética. Essa seria "a teoria que permite o controle de todo planejamento possível e de toda organização do trabalho humano" (Heidegger, 2009, p. 68), ela transformaria a linguagem em um meio de troca de mensagens e, as artes, em instrumentos controlados e controladores da informação. Ela teria como propósito tentar compreender como se dá a comunicação e o controle dos seres vivos, de seus grupos, e das máquinas. Caberia à linguagem - no sentido de informação - a possibilidade dessa função de controle, no sentido de determinação dos costumes sociais. 
Nesse ponto, reencontramo-nos com a ideia de linguagem como Gestell (com-posição). Com a linguagem limitada à função de informação, até mesmo a própria arte acaba, porque deixa seu lugar de origem e torna-se um instrumento calculante. Walter Benjamin (1994), em O Narrador, discorre sobre uma forma de comunicação de origem antiga e que se consolidou com a burguesia, influenciando a forma épica da narrativa e do romance, chegando a ameaçar e a provocar crises. Essa nova forma de comunicação seria justamente a informação. À informação interessa o que é próximo no tempoespaço. Isso a faz dispor de uma impressão de autoridade que, para sustentar essa posição, necessita manter-se compreensível "em si e para si" - por isso precisa ser plausível. Esse seria o ponto primordial em que a informação se diferiria da narrativa, e, com ela, a possibilidade de deixar certos aspectos em aberto - preferindo a informação, que já vem fechada.

A Era Atômica necessitava de rapidez para produzir e estocar cada vez mais, e manterse, assim, segura. Já a informação necessita ser rápida, sem perda de tempo, pois precisa ser nova para que tenha valor. Logo, observamos que a primeira caracteriza-se pela segunda, por intermédio da questão da velocidade e da necessidade de produzir garantias sobre si mesma. Assim, a informação torna-se mais rápida e mais nova com o auxílio do desenvolvimento tecnológico, que, a partir dessa era, acarretou um enorme salto científico.

O conhecimento precisa da informação para gerar a produção necessária e também para agilizar essa produção e aumentar sua capacidade de armazenamento. Podemos, a partir de então, observar a ligação anterior e como ela torna-se crucial na forma na qual o pensamento calculante encontra-se. É por meio da informação que nos comunicamos, mas não apenas isso. É por meio dela que o mundo vem tornando-se cada vez mais rápido, mais inequívoco, mais produtivo - no sentido de salvaguardar suas necessidades, carências e satisfações, tal qual era o objetivo da Era Atômica - e que mantemos até hoje.

Conforme Heidegger (1957) já chamou a atenção, a informação é a peça-chave para que a técnica salvaguarde-se. E se a própria linguagem é transformada em um meio de troca de mensagens (2009, p. 68), a linguagem torna-se informação. É por meio desta que surge como possibilidade a criação de "máquinas pensantes" e equipamentos de cálculo extensivo. Porém, ao mesmo tempo que comunica, que transmite, a informação também institui. Dessa maneira, todos os objetos e as existências são postas ao Dasein como se este pudesse salvaguardar seu domínio sobre a totalidade da Terra e até do que estaria além. A informação funciona como uma palavra de ordem que visa a induzir o pensar e o viver à luz da homologização no meio digital (Almeida, 2007).

Neste momento, encontramo-nos com a técnica, compreendendo-a como determinadora de nosso mundo para que este seja tal qual é. No entanto, apesar de seu caráter determinador poder dar uma impressão de temporalidade, ela conclama para si a ideia de ser atemporal. Nessa tentativa de se apresentar como atemporalidade, aparece-nos como se sempre tivesse existido, criando para si uma imagem de verdade e de imutabilidade. Ela utiliza-se dessa imagem para poder garantir-se em seu futuro e, assim, conseguir manter sua posição. Para tal fim de se salvaguardar, coloca em jogo a própria 
historicidade do Dasein, pois uma vez submerso na técnica ele perde completamente essa relação com a sua história.

Apesar dos esforços da técnica para nos distanciar de nossa própria historicidade, ou seja, para separar Dasein do mundo, devemos manter em aberto a capacidade de pensarmos historicamente. Isso significa colocar-nos na posição de espera. Contudo, essa espera não é passiva, como o verbo "esperar" sugere. Ela é uma espera pelas transformações da história. É função do pensamento colocar-se nesse lugar extremamente problemático, da tensão com a mobilidade histórica do próprio tempo.

Heidegger afirma (2009) que pensar não é se colocar passivamente em relação à história e esperar que esta se transforme para que nós possamos dar voz a ela. Se a isso fizéssemos, estaríamos apenas em uma posição de observadores. Para ele, pensar é estar em crise, o que significa justamente possibilitar que as estranhezas façam-se presentes em um mundo tão dominado por familiaridades. Pensar significa colocar-se nesse lugar de crise a partir do qual a história pode se rearticular. Por isso a posição do pensamento é uma posição de vigília, de guarda em relação à história. Mas ela não se transforma por nosso desejo, a história tem um tempo que é dela e que se modifica para além de nossos anseios.

Sobre a questão das transformações em relação à história, uma forma de pensarmos esse assunto é considerarmos que para mudarmos o que está à nossa volta basta mudarmos a nós mesmos. Outra maneira como podemos conceber suas transformações seria oposta à anterior, de que é necessário mudarmos o mundo para que possamos mudar a nós mesmos. Mas em ambos os casos o responsável pela mudança seríamos nós mesmos, pois se somos nós quem mudaríamos o mundo para então podermos nos mudar, também o somos quando queremos mudar a nós mesmos para transformar nosso entorno.

A posição de Heidegger (2012) sugere que não podemos controlar nenhuma dessas mudanças, nem do Dasein nem do mundo, por nosso desejo. Em seus trabalhos posteriores a Ser e Tempo (2008), a forma de encarar essas questões sofre uma modificação - por mais que o Dasein transforme-se, ele não transforma o mundo. Ele precisa da transformação do mundo para poder ser transformado, pois, embora os dois sejam coexistentes, é o mundo que abre as possibilidades de transformação para o Dasein. Por esse motivo, não podemos descartar a importância do horizonte histórico ao pensarmos uma construção de subjetividade, entendendo-a como a reflexão acerca das problemáticas que giram em torno do acontecimento e de suas relações de poder em conjunção com a produção de sujeitos ou de subjetividade, sofrendo clara influência do pensamento heideggeriano e/ou nietzschiano. Costuma-se pensar que, na modernidade, o primeiro filósofo a traçar um conceito de subjetividade foi o dinamarquês Soren Kierkegaard. Ao nos debruçarmos sobre a obra heideggeriana, podemos pensar que a trama conceitual de sua obra nos aporta uma preocupação acerca da produção de subjetividade pelo viés de um entendimento do jogo profuso entre o pensamento, a técnica, o acontecimento e o Dasein, por exemplo.

A técnica é, assim, uma requisição histórica. Ela é um modo de a história interpelar o Dasein. A morada do Dasein é histórica, ou seja, 
não podemos pensá-lo sem pensarmos o horizonte histórico que o circunda. Exatamente por isso, ele precisa ser requisitado pela história para que ele possa, a partir de então, encontrar o lugar em que ele se encontra. Por isso, para Heidegger, o ponto de partida para qualquer questionamento, para qualquer pensar sobre o que nos cerca, é o horizonte histórico.

Não podemos fugir desse horizonte que é o nosso e que nos determina também como os Daseins que somos. Cada horizonte histórico é marcado por acontecimentos que determinam como o Dasein posiciona-se perante a sua história e a si mesmo. Nesse caso, pensar também significa pensar as determinações históricas que determinado tempo nos traz. Se nosso horizonte histórico é o da técnica, é por meio da técnica que devemos embasar-nos. É ela quem nos caracteriza, conforme trouxe Heidegger (2012). Nós, ao contrário dos animais, estruturamos toda a nossa vida a partir dela. Ela torna-se, dessa maneira, nosso ser, e como o Dasein é esse ente que sempre se determina em seu ser a partir do horizonte no qual ele encontra-se desde o princípio jogado, é a partir da técnica que ele define-se neste horizonte no qual encontramonos agora.

Entretanto, não nos basta pensarmos a técnica em nosso horizonte histórico. É preciso que tenhamos em mente que pensar é pensar a essência da técnica, por isso, a meta torna-se pensar a essência da técnica nesse horizonte histórico que é o nosso e que é, justamente, técnico.

\section{A técnica}

Para abordarmos a questão da técnica, é interessante que comecemos expressando o pensamento calculante. Ele encontra-se relacionado com o cálculo, com o contar. No entanto, não em um sentido matemático, como podemos ser levados a entender, mas com o sentido de contar com alguma coisa, ou seja, o próprio princípio da ideia de calcular. Heidegger (1957), pensando o princípio do fundamento, cita a frase nibil est sine ratione, o que significa, nada é sem fundamento.

O princípio do fundamento seria o mais vazio e enigmático de todos os princípios. É justamente na proximidade, na familiaridade, na não necessidade de explicação, exatamente onde pensamos que conhecemos tudo o que é relativo à determinada coisa e nada pode ser-nos estranho é que encontramos os estranhamentos mais difíceis de serem observados. Somente em um olhar para além do pensamento calculante é que conseguiremos captar de uma outra forma aquilo que sempre esteve ali.

A esse fundamento é esperado que seja suficiente e que baste plenamente para poder, dessa forma, salvaguardar um objeto na sua posição. Se ele não se bastar, se não for suficiente, sua garantia de salvaguarda ficará ameaçada. Assim, é necessário que ele ao menos pareça claro e completo, que não abra suspeitas sobre si para que suas garantias sejam válidas e que ele sirva para o fim que lhe foi destinado. "O fundamento dá a conta para a verdade do juízo. Conta chamase em latim ratio" (Heidegger, 1957, p. 169). Temos assim nossa aproximação com a frase Nibil est sine ratione. Ratione, ratio. O fundamento é ratio, o que quer dizer, ele conta. O homem/a 
mulher é o animal rationale. Ele/a é o ser vivente, que exige e dá conta, logo seria o ser vivente contador (Heidegger, 1957, p. 183).

O que queremos colocar em evidência é que apesar de ser o fundamento aquilo que sustenta a verdade de juízo, o juízo não é uma verdade. Ele só passa a ser verdade quando a conta, ou seja, a ratio, é prestada. Essa prestação precisa, antes de ser prestada, de um lugar onde esteja depositada. É nesse momento que chegamos ao homem/à mulher, pois é para ele/a que o fundamento deve ser devolvido - uma vez que é ele/a que define os objetos como objetos. A conta só é conta como conta prestada. O fundamento é apenas um tal fundamento como a conta que é prestada sobre algo perante o Dasein. Assim, é o Dasein que, sendo o animal rationale, é aquele que exige e dá conta.

No entanto, ainda não se faz claro o que é esse "ratio" que tanto vem se mostrando. Para tal fim, Heidegger (1957) faz remissão aos tempos de Cícero, expondo que a palavra (contar) é o sentido vasto do ratio. Ela originalmente pertencia à linguagem de negócios romana e fora transposta dos gregos. Contar significa então "contar com" algo, sem considerar as possibilidades desse algo não ser como se deseja que ele seja. Isso significa que esse "contar com" não se refere a considerar as imprevisibilidades. Conta-se que algo ocorrerá de uma determinada maneira e, sendo assim, conta-se com determinado fim. Ou seja, antes que algo existisse como realidade, contava-se com a expectativa daquilo tornar-se real, antecipando os próprios acontecimentos. Por exemplo, ao

\footnotetext{
${ }^{3}$ Heidegger, a partir da década de 1930, utiliza-se de um recurso de diferenciação de grafia para a palavra "ser" com o intuito de especificar quando se refere à questão da metafísica acerca do ser, compreendendo-o
}

contar com alguma colheita para o próximo ano, desconsiderava-se a possibilidade de seca, de tempestades fortes, pragas, de qualquer coisa que fosse externo, mas que influenciasse naquela colheita, ou seja, conta-se com, antecipando algo que ainda não se deu. Dessa maneira, retornando à frase de que o fundamento dá a conta para a verdade do juízo, devemos ter em mente de que o juízo não é uma verdade. Ele a seria só “quando é dado o fundamento da conexão, quando a ratio, isto é a conta é prestada. Uma tal prestação necessita de um lugar onde a conta esteja depositada antes de ela ser prestada" (Heidegger, 1957, p. 170).

Podemos inferir que a razão, isto é, a conta, é uma medida que se tem, que antecipa os desdobramentos do que está por vir. Ela antecipa os desdobramentos do que vem justamente porque se antecipa a si mesma. No momento em que desconsidera as imprevisibilidades que podem surgir de uma determinada situação, produz o seu próprio futuro em seu presente, na tentativa de se manter garantida. Assim, estamos já no campo da técnica.

Em Meditação (2010b), Heidegger apresenta o termo Machenschaft (maquinação) como sendo a factibilidade do ente - o que seria passível de ser feito, com vistas à possibilidade de que tudo seja feito. Seria nela que a entidade do ente abandonada como seer $\left(S_{\text {eyn }}\right)^{3}$ seria determinada pela primeira vez. A essência desta seria constantemente aniquiladora - uma vez que se utiliza da ameaça e da aniquilação em seus desdobramentos - e, assim, sua essência seria a

como o ente supremo e como o fundamento último da realidade. 
violência, que se desenvolveria no asseguramento do poder como capacidade e submissão a este. Dessa forma, Machenschaft seria o impedimento e o soterramento de toda decisão, arrastando para si de forma antecipada tudo o que é factível.

A técnica moderna emergiria da exigência essencial, mas ao mesmo tempo velada, de uma calculabilidade exigida de antemão. Ela necessita inserir-se no factível como sujeito cofeitor, ou seja, aquele que faz com, e, para isso, possibilita ao Dasein um arrebatamento à articulação de sua essência de massa, em que toda particularização humana é superpotencializada. Essa técnica necessita previamente contar com algo para que possa parecer que se faz com o Dasein. Dessa forma, só resta a este, como ser vivo, a "vivência" como comportamento instituído que lhe oferece a aparência da autoafirmação ante $o$ ente na esfera da Machenschaft.

Entendemos, com o aumento da amplitude e da velocidade, assim como o modo comedido e público do "vivenciar", que as últimas barreiras para a violência da Machenschaft caíram. Desse modo, a chamada era da consumação da modernidade, compreendendo consumação como apoderamento irrestrito, já teria como consequência essencial o poder da técnica sobre o ente e sua impotência ante o seer e, logo, não poderia estabelecer a técnica como seu fundamento. Devemos lembrar que o predomínio da Machenschaft é atualizado pela história. É na modernidade que essa supremacia incondicional é consumada e, em nosso tempo, começam a não satisfazer mais com tanta eficácia.

Para tratarmos sobre o assunto da técnica, temos de deixar claro que ela não é igual a sua essência, já que nenhuma essência é igual a seu objeto. Por exemplo, ao pensarmos em uma pedra, não é possível alcançarmos a essência desta, pois teremos a ideia apenas daquela que imaginamos, mas nunca todas as pedras como elas se mostram -, assim como sua essência não é, de modo algum, algo de técnico. Não existe nenhuma técnica que nos faça poder compreender ou sentir essa essência. Logo, não podemos olhar para algo e esperarmos ver ali sua essência. Mesmo que nos utilizemos das mais variadas técnicas específicas para esse fim, pois se a essência não é algo técnico, não é de forma técnica que a compreenderemos.

Essa diferenciação mostra-se importante desde as primeiras considerações a respeito desse tópico, uma vez que, para Heidegger, costumamos pensar sempre acerca da técnica, mas deixamos de lado a questão sobre sua essência, o que faria total diferença entre nosso entendimento e relação com ela. Por não pensarmos essa questão, mantemos esse tipo de relação ausente de liberdade com ela, pois somente um refletir sobre o assunto poderia fazer-nos relacionar com sua essência - e assim mudar também nossa relação com a própria técnica -, já que esse refletir é justamente o que nos abriria para novas formas de a compreendermos. Em resumo, ao questionarmos, a técnica estamos perguntando o que ela é.

Duas possibilidades são comumente aceitas em resposta a essa indagação: 1. Afirmar que ela é um meio para um determinado fim. 2. Alegar que ela é uma atividade do Dasein. Contudo, essas duas alternativas pertencem-se reciprocamente, pois o ato de estabelecer fins, de procurar e usar meios para conseguir e os alcançar é uma atividade humana. A produção e o uso de 
ferramentas, aparelhos e máquinas são pertencentes à técnica, assim como esses produtos e utensílios em si mesmos e as necessidades as quais eles servem. Todo esse conjunto é a técnica. Ela própria é também um instrumento. Essa seria uma determinação instrumental e antropológica da técnica, em que ela serviria como um instrumento para uma atividade humana. Definição essa que em um olhar descuidado sobre ela podemos, inclusive, considerar correta, sem que nada nos aparente ser estranho nessa afirmação.

Por ela mesma ser também um instrumento e por tudo o que é pertencente a si, como suas ferramentas, por exemplo, o Dasein passou a confiar que é capaz de manipulá-la, de dominá-la - e quanto mais ela ameaça escapar ao controle deste, mais ele a quer controlar, afirmando que ela é um instrumento dele e está sob seus serviços e ordens. O que é fácil de percebermos e até confirmarmos se olharmos superficialmente para essa questão. Supostamente a ordem lógica é de que o Dasein, com sua capacidade mental e comunicativa, criou a técnica como um meio de conseguir seus fins, logo, a técnica não passaria de seu instrumento. Visivelmente teríamos uma posição neste caso: a do Dasein pensante e soberano de si e do mundo, tendo a técnica como submissa, que só existe para atender às suas vontades. O que deixamos de pensar, ao relacionarmo-nos com a técnica em nossa forma habitual, é a possibilidade de que ela não seja somente um simples meio. Não obstante, teríamos de questionar sua essência - que continua oculta por trás da determinação instrumental da técnica. Pensar sua essência também significa refletir sobre as determinações do tempo. Mas esse tempo não nasceu agora. O fato de existirem essas descobertas tecnológicas atuais não é capaz de mostrar a centralidade dessas descobertas na existência que é a nossa. A questão sobre o motivo pelo qual, em nosso tempo, a técnica mostra-se tão central continua sem a devida atenção quando não pensamos a medida do agora e sua medida histórica.

Assim sendo, o que Heidegger (2010b) tenta pensar é a historicidade do horizonte histórico. A história poderia ter sido de qualquer jeito, o tempo de agora poderia ser qualquer um. Mas a questão é pensar, dentre todas as possibilidades que o presente poderia ser, esse que ele é, e como nós nos relacionamos com esse mesmo. Esse tipo de pensar diferencia-se de uma criação de teoria. Estas, procuram conceitos verdadeiro se, com isso, acabam aproximandonos de supostas verdades naturais e inabaláveis como a de que a técnica é um instrumento do Dasein.

$\mathrm{Na}$ tentativa de entender melhor sobre esse assunto, a Filosofia, a partir de Aristóteles (Heidegger, 2012), propõe a compreensão das quatro causas - um exemplo da tentativa de se teorizar, no sentido de fixar, interpelar e construir proposições sobre esse assunto que envolve a técnica - que seriam a causa materialis: o material, a matéria de que se faz; a causa formalis, a forma, a figura em que o material é inserido; a causa finalis, o fim, a finalidade; e a causa efficiens, o produto realizado (Heidegger, 2012, p. 13), ou seja, aquele que produz o efeito. Dessa maneira, a causalidade, a instrumentalidade e a determinação corrente da técnica, que se faziam parecer tão claras e verdadeiras por séculos na Filosofia, se mostrarão obscuras e sem fundamento. Heidegger começa salientando o encurtamento dessa questão aristotélica das quatro causas, já que não se 
pergunta mais com essa questão. Pensa-se sempre como causa eficiente e articula-se a ideia de causa com a ideia da produção de um efeito. Logo, em nosso tempo, só aquilo que tem uma efetividade, o que funciona, o que consegue comprovar os seus efeitos é o foco do pensamento.

Essa doutrina das quatro causas remonta-nos a Aristóteles, porém "tudo o que a posteridade procurou entre os gregos com a concepção e o título de 'causalidade' nada tem a ver com a eficiência e a eficácia de um fazer" (Heidegger, 2012, p. 14). Lembrando que viemos concebendo a causa como o que é eficiente há bastante tempo, e, por esse motivo, a finalidade deixa de pertencer à causalidade.

No entanto, para os gregos, "as quatro causas são os quatro modos, coerentes entre si, de responder e dever" (Heidegger, 2012, p. 14), levando alguma coisa a aparecer. Assim, deixam que algo vigore, soltando algo em sua vigência, em seu pleno advento. Esse deixar, responder e dever são, assim, um deixar-viger. Esse deixarviger sendo compreendido em um sentido mais amplo, possibilitando evocar a essência grega da causalidade. Compreendido aqui de forma mais abrangente, ajuda a percebê-lo evocando a presença grega de causalidade, pois se nos permitíssemos o perceber apenas em sua forma mais restrita, e até mesmo mais cotidiana, ele se relacionaria mais com oportunidade e ocasião ligando-se assim a um tipo de causa secundária no total da causalidade. Desse modo, todo deixarviger, conforme Heidegger (2012) mostrou-nos em Platão citando um trecho do Banquete, a produção é o que passa e procede do não vigente para a vigência.

Em outras palavras, no interior do mundo grego ainda há uma relação entre technè - como um saber fazer, um dominar todos os momentos do processo de produção de algo -, e poiesis, que inicialmente estaria ligada à criação - a própria produção desse algo. Toda poiesis envolve uma technè e uma episteme, ou seja, uma técnica e um conhecimento técnico, tal qual apresenta Heidegger (2012). Para melhor visualizarmos essa questão pensemos, por exemplo, nas artes. A manifestação artística pede um conhecimento técnico e uma técnica acerca do que está sendo criado. Por exemplo, na dança é preciso que tanto o coreógrafo quanto o bailarino conheçam as técnicas que dizem respeito à sua arte: a postura corporal, as posições, o nome destas, já que, quanto maior for seu conhecimento técnico e sua técnica propriamente dita, melhor poderá movimentar-se tanto no processo de criação como no de interpretação de uma coreografia.

De acordo com Heidegger (2012), quando é feita essa articulação, faz-se o movimento de trazer do não ser ao ser, que é como Platão define poiesis: produção. Nesse ponto, surge a articulação entre técnica e verdade, pois verdade, no mundo grego, significa justamente esse movimento, ou seja, desvelamento, alethéia - que os romanos traduziram por veritas.

É importante nos determos nos conceitos de alethéia e veritas para que possamos compreender como pensar a verdade, em cada um desses conceitos. Alethéia guarda em seu nome o "a", que traz a ideia de negação, e o "lethe", que se refere ao esquecimento. Refletir sobre o não esquecido remete-nos a pensarmos a existência de um esquecido. Por esse motivo, ela associa-se ao conceito de desvelamento, pois, enquanto algo é desvelado, outro é velado em um jogo de velar e desvelar, em que não é possível termos acesso a 
um conteúdo por inteiro (Heidegger, 2012). Ou seja, quando olho para uma folha posso ver apenas uma página desta. A página que olho desvela-separa de mim, enquanto seu verso encontra-se velado. Não posso, ao mesmo momento, desvelar os dois lados. Alethéia, então, é movimento. Dessa forma, a verdade que ela apresenta, que se mostra em seu desvelar, não pode ser uma verdade fechada, total, nem imutável. Poderíamos considerar mais precisa a ideia de que algo está sendo verdade - ao contrário de afirmarmos que algo é verdade. Outra característica dessa forma de verdade é que ela permite que o que se mostra apareça a partir de si mesmo.

Já veritas abandona a questão de que algo é velado no momento de um desvelamento. Ela não mantém o movimento presente na alethéia e, justamente por isso, fecha a verdade como algo sólido, substancial e sem margem de dúvidas. Nesse momento, desconsiderando o que se vela, o que se desvela aparece como verdade absoluta. E, contrariamente da alethéia, em vez de algo ser compreendido a partir de si, ela parte de uma compreensão do sujeito por esse algo.

Percebemos que a tradução romana de alethéia por veritas transforma não somente $\mathrm{o}$ conceito de verdade, mas a forma com a qual lidamos com ela. Por meio da veritas, perdemos o movimento e a instabilidade da verdade, uma vez que não há garantias do que poderá ser velado ou desvelado no jogo do desvelamento. Sendo assim, conseguimos vislumbrar que veritas e pensamento calculante são conceitos afins. Logo, a técnica agora aparece como um modo da verdade e da produção da verdade. É por intermédio dela que a verdade, como veritas, manifesta-se aparentemente esquecendo-nos de que no momento em que uma coisa é desvelada outra é velada, logo, que nada pode ser e nem ficar totalmente desvelado. Mas, apesar de Platão ternos indicado que ela era verdade, ainda não sabemos que tipo de verdade é essa. A questão que se faz presente nesse momento é o que viria a velar-se no instante em que o produto é o que é desvelado. Não há nada mais que não seja produção. Uma produção insaciável que jamais se contentará consigo mesma nem com nada, que desafia a natureza e a nós mesmos a sermos qualquer coisa que a técnica quiser que sejamos.

Voltando ao tema central, ao indicarmos "verdade", entendemos como o correto de uma representação daquilo que foi desvelado. Portanto, o pensamento "ser é produção" está longe de ser atual no sentido de ser algo surgido especificadamente em nosso tempo, pois já se é ensinado que no vigente existe o eclodir da produção. Assim, os modos do deixar-viger, as quatro causas jogam no âmbito da pro-dução e do pro-duzir. "É por força deste último que advém a seu aparecimento próprio, tanto o que cresce na natureza, como também o que se confecciona no artesanato e se cria na arte" (Heidegger, 2012, p. 16). É no desvelar que repousa a possibilidade de toda elaboração produtiva. É nele que se funda toda a pro-dução. Dessa forma, vemos que a técnica não é um simples meio, mas uma forma de desvelamento, ou seja, uma forma da verdade.

A técnica moderna distancia-se em muito de toda a técnica anterior, já que ela se apoia na moderna ciência exata da natureza, assim como a ciência experimental depende de aparelhagens técnicas e do progresso na construção de aparelhos. Essa aproximação da técnica moderna com a ciência não faz com que a primeira deixe de ser, assim como suas antecessoras, um 
desvelamento. "O desvelar, que rege a técnica moderna, é uma exploração que impõe à natureza a pretensão de fornecer energia, capaz de, como tal, ser beneficiada e armazenada" (Heidegger, 2012, p. 19). A técnica moderna continua como um desvelamento, porém a forma de desvelamento e do que é desvelado é o que muda. Heidegger, em A questão da técnica (2012), exemplifica as diferenças entre o extrair da terra somente aquilo que ela pode nos ofertar, e o contraposto técnico, de querer retirar da terra algo que, naturalmente, não seria oferecido. Sendo assim, depreendemos como o trabalho camponês não provoca nem desafia o solo agrícola. Ele não espera da terra que ela the dê algo para além da colheita de sua plantação. Ele lavra-a no sentido de cultivar e de proteger. Hoje em dia, com a indústria motorizada da agricultura, plantar e colher recebem um significado diferente do anterior. A natureza já é colocada como disponibilidade no sentido de uma exploração. "Esta dis-posição, que explora as energias da natureza, cumpre um processamento, numa dupla acepção. Processa à medida que abre e ex-põe" (Heidegger, 2012, p. 19). O camponês, como é compreendido hoje, deve não somente cultivar e proteger sua terra, não somente plantar suas sementes e esperar que elas nasçam sem nada mais fazer - no sentido de estar inserido em um mundo técnico capitalista de concorrências e necessidade de produção em larga escala. Ele agora precisa explorar sua terra, entendendo por exploração o ato de esperar dela mais do que ela pode oferecer. Necessita, portanto, de um maquinário. A terra agora precisa mostrar-se a postos, disponível, para o camponês. Dessa forma, "extrair, transformar, estocar, distribuir, reprocessar são modos de desvelamento" (Heidegger, 2012, p. 20).

A técnica passou a inserir-se em nossas vidas nos trazendo uma mudança radical na forma com a qual lidávamos com a terra. A terra, para nós, não se mostrava mais a mesma. Não bastava mais que ela oferecesse o que sempre ofereceu. Precisava oferecer mais. O homem/a mulher, que desde seus primeiros passos por este mundo utilizava-se da natureza para sobreviver, passou a querer produzir para além dela. A partir dessa mudança, podemos notar claramente o ingresso no mundo técnico. Essa transformação que se crê ter dado de forma natural como o lógico a ser feito no processo de evolução humana, marca uma ruptura na forma com a qual o Dasein lidava com o mundo a seu redor.

O disponível (Bestand) é o modo como o ente aparece agora no interior do horizonte da técnica. Bestand também significa encomenda. Ao encomendarmos alguma coisa, fazemos o pedido de algo que ainda não existe, contando que na data determinada o produto esteja lá, disponível para nós. Esse lugar onde fizemos o nosso pedido mostra-se a postos para encomendas desse tipo. Porém, esse dispor, encomendar, estar a postos não se faz presente somente com objetos, o próprio Dasein também se encontra nessa posição. Ao analisarmos esse posicionamento da disposição, reencontramo-nos com a palavra Gestell, esquema posicionador, o tipo de desvelamento da técnica moderna, mas que, em si mesmo, não é nada técnico, traduzido para o português como com-posição. Gestell significaria, assim, "o apelo de exploração que reúne o homem a dis-por do que se des-encobre como disponibilidade” (Heidegger, 2012, p. 23). 
Esse termo, para Heidegger, nomeia a própria essência da técnica moderna, uma vez que coloca o que o cerca como sua disponibilidade. Portanto, é essencial em nosso horizonte histórico. Ele proporciona a experiência do ser como disponibilidade, da natureza como fundo de reserva, como matéria-prima, como algo que, posteriormente, podemos lançar uma demanda de extração, de controle. Costumamos relacionar essa demanda como sendo provinda de nossa própria vontade, mas, no entanto, ela corresponde ao apelo, que seria o próprio Gestell e que, por fim, seria o próprio Ereignis, ou seja, acontecimento.

Gestell poderia ser aproximado a um negativo fotográfico do Ereignis, ou seja, apesar de a imagem naquele negativo estar invertida, ela continua sendo a mesma imagem. É característica sua encobrir-se como acontecimento, mas isso não faz dele menos acontecimento, tal qual o negativo de uma fotografia não a faz menos fotografia. Observamos com isso que mundo, Dasein e linguagem mostram-se como disponíveis, necessitando estar a postos às questões técnicas.

Por esse motivo, podemos perceber que a técnica não se reduz somente a uma atividade humana, porque o Dasein precisa já ter sido desafiado a explorar as energias da natureza para que o desencobrimento da dis-posição possa se dar. Logo, somos levados a cogitar algo que precederia a atividade humana. Isso faz-nos pensar como o Dasein pode ser aquele que domina, que requisita o disponível se ele já se encontra totalmente absorvido nesse espaço no interior do qual algo se mostra como disponível. No entanto, fica a questão de quem, se não for o Dasein, realizaria o posicionamento requisitor por meio do qual aquilo que se denomina o efetivamente real é desvelado como disponível. O Dasein participa da dis-posição, como um modo de desvelamento, ele vê-se desafiado, de forma especialmente incisiva, a comprometer-se com esse desvelamento, ao realizar a técnica. Até mesmo quando quer contradizer a esta, o Dasein apenas responde ao apelo do desvelamento.

Por ser um desvelamento da disposição, já que revela apenas o lado que se faz interessante a ela ser visível, que é justamente o do estar disponível, a técnica moderna não se reduz a um mero fazer do Dasein. Esse espaço no qual ela habita é o espaço onde tudo se dá agora. Então, não há a possibilidade de ser o senhor desse lugar. Entretanto, nos encontramos sob o domínio dessa determinação histórica. Uma vez que, para se manter na posição que hoje ocupa, a técnica precisa fazer parecer que ela é a verdade, o único caminho e tudo o que necessitamos. Podemos intentar que não há nenhuma possibilidade de se escapar dela e de sua forma absorvente de querer capturar o que está ao seu redor para o seu interior. Ou seja, ela tende a dissipar aquilo que não pertence a seu modo de funcionamento. Dessa forma, para ser sobrevivente em um mundo técnico, faz-se necessário que se siga alguns preceitos calculantes. Com essa necessidade clara, a técnica expande-se - pois quem quiser continuar a existir apoiado por sua certeza deve submeter-se a ela. Ela é incontrolável porque quando se coloca, já domina. Nesse aspecto, ela é completamente absorvente.

Não somos nós quem determinamos a técnica, mas seu horizonte que nos determina. Concebemos com isso que a técnica não está mais em nossas mãos, sob nosso controle, ela não é mais instrumento. Recordando que a técnica não se reduz a uma atividade humana, pois o Dasein 
necessita já ter sido desafiado, surge a ideia de algo prévio ao controle do Dasein. Algo que o desafia, até porque não há lugar para além do desafio. Sendo assim, nos é possível constatar que ela não é mais um instrumento que existe para o nosso uso, mas que ela dá instrumentalidade, uma forma de produzir causa e efeito.

A técnica é incondicionada. Não tem limites, não depende de nada. Ela é insaciável, já que todo processo técnico abre espaço para um outro espaço - como tão bem podemos constatar nos campos das especializações. Cada campo que surge é uma infinidade para novas determinações técnicas e descobertas de novas áreas. A partir desse momento, observamos que servimos para dar vazão a esse propósito técnico. Possibilitamos que ela mantenha-se tal qual é e fazemos de tudo para a garantir em seu futuro. Portanto, concebemos o pensamento de que nós é que somos seu instrumento.

Como a técnica é o horizonte histórico no qual nos encontramos, tudo passa por esse caminho. Sendo assim, nós também somos absorvidos por ela. Recordemos a necessidade de ela garantir-se em seu futuro, mesmo que as condições the sejam as mais desfavoráveis. De que o descobrimento da dis-posição só pode ser dado se o Dasein já houver sido desafiado. Que tudo necessita de seu crivo para poder se desenvolver em nossos tempos. Deduzimos então que somos utilizados em seus meios e fins, pois quem dissemina a ideia de que as coisas devem ser desse jeito somos nós. Nós que queremos sempre o mais novo, o mais rápido, o mais tecnológico. Nós que estudamos, dedicamos toda a nossa vida para garantir que a técnica esteja segura e cada vez mais desenvolvida.
Destarte, aparenta não ser mais possível mantermos a ingenuidade de que ela é nosso instrumento e que só a utilizamos porque é de nosso interesse, conforme Heidegger (2012) apresentou-nos. Seu tempo e espaço são distintos dos nossos. Ela só quer se garantir, continuar sendo o Caminho para todos os caminhos e, para isso, nenhum instrumento mostra-se melhor utilizável do que o Dasein. Não conseguimos relacionar-nos livremente com ela. Não é possível viver em um mundo onde ela não esteja presente. Temos dificuldades, até mesmo, de imaginar uma outra forma de existirmos - neste momento podemos perceber como nossa relação com ela não se mostra livre. Necessitamos dela a cada dia, a cada instante.

A técnica nasce exatamente da automatização da subjetividade técnica. Ela é sujeito posicionador. É uma estratégia sem estrategista. A subjetividade técnica é impessoal, não existe alguém por trás dela comandando-a, direcionando-a. A técnica suprime a ideia de ser, e tanto alimenta quanto se alimenta do esquecimento ontológico - referente ao ser e à diferença entre ser e ente. Dessa forma, o Dasein se compreende como algo fechado e acabado, que tem um destino e constrói uma história, já que a automatização da subjetividade técnica implica também em uma automatização do Dasein em seu cotidiano. Esse destinar, para o Dasein, significa o pôr a caminho. Destino seria assim "a força de reunião encaminhadora, que põe o homem a caminho de um desencobrimento. É pelo destino que se determina a essência de toda história" (Heidegger, 2012, p. 27). E não somente a essência de toda história, mas também a essência da técnica moderna. 
Pensamos assim o sentido de essência. A composição é onde essa essência repousa. Ela é um modo destinado de descobrimento, desencobrimento da exploração e do desafio. Com-posição torna-se a essência da técnica, por ser destino de desencobrimento - e não no sentido de gênero e de essentia. Levando isso em conta, a própria técnica exige de nós pensar o que, em geral, se chama de "essência" num outro sentido (Heidegger, 2012, p. 32).

Testemunhamos, portanto, que a técnica está para além do Dasein, fazendo-o crer que ele está no controle e que, com ela, ele também está para além de si. Para além de uma muleta na qual o Dasein poderia apoiar-se em caso de necessidade, a técnica já passa a ser uma prótese - e isso faz-nos pensar porque se torna tão complicado não darmos tal importância e soberania ela. Assim, podemos compreender que essa forma de pensamento pretende fazer-se tão natural e, ao mesmo tempo, super-humana, tão necessária, que chegaríamos ao ponto de sermos levados a não questionarmos, ou seja, a não refletirmos sobre a essência nem da técnica, nem das coisas que nos cercam - incluindo a do próprio Dasein.

Para Heidegger (2009), pensar é estar em crise no sentido em que somos retirados de nosso lugar de conforto que é o que nos é familiar. Ao não questionarmos, ao não pensarmos sobre as coisas, acabamos tendo dificuldades em ver estranhamentos em meio a um mundo que julgamos tão familiar. Com essa familiarização de tudo e de todos/as, acabamos impedidos de sermos livres em nossa relação com o horizonte histórico no qual nos encontramos. Essa afirmação sustenta-se, pois seria justamente essa saída do lugar que nos é comum, que nos é familiar, que nos possibilitaria um certo distanciamento. Com esse distanciamento, conseguimos enxergar de maneira já não tão habitual aquilo que antes nem nos chamava a atenção dado à imensa proximidade. No momento em que estamos em familiaridade com as coisas, ou seja, sem estranharmos o que está a nossa volta, tomamos tudo como dado e aceitamos que "é assim porque é assim", sem cogitarmos possibilidades de outras formas de ser. No momento que só conseguimos nos relacionar com o mundo de uma forma já previamente dada, não somos capazes de escolher de que forma essa relação pode se dar, por isso não conseguimos ser livres desta.

Estaria ligado ao pensamento calculante $o$ ato de nos esquecermos das contingências julgando as coisas como universais. Um exemplo muito claro, e também clássico, dessa tentativa de julgar as coisas como universais podemos ver quando Schlick nos resume o princípio da causalidade, apresentado por Maxwell, na frase: "O princípio da causalidade se cumpriria em todas as circunstâncias ou eventualidades" (Schlick, 1980, p. 12). Apesar do próprio Schlick considerar essa frase uma tautologia, pois "uma proposição que vale para qualquer sistema, como quer que ela seja, não diz absolutamente nada acerca do sistema em questão, é vazia, representa uma pura tautologia" (1980, p. 12). Porém, o que queremos trazer aqui é que o princípio da causalidade - no qual primava que em condições iguais os processos e eventos seriam sempre iguais - foi uma forma encontrada pela Física de se estabelecer como ciência lógica e exata. Esse princípio a ajudou na formulação de suas teorias e averiguação de seus dados. A meta da ciência nunca foi buscar as diferenças que tornavam cada 
acontecimento ser tal qual ele fora, mas sim buscar o igual, aquilo que eles tinham em comum, na tentativa de poder universalizar os fatos para que, dessa forma, pudessem prevê-los e, quem sabe, controlá-los.

O modo de representação da ciência encara a natureza como um sistema operativo e calculável de forças (Heidegger, 2012, p. 24). A Física moderna pode ter abandonado, ou mudado sua concepção sobre a representação de objetos - único procedimento decisivo para a Física tradicional -, mas não consegue renunciar “a necessidade de a natureza fornecer dados, que se possa calcular, e de continuar sendo um sistema dis-ponível de informações" (Heidegger, 2012, p. 26). Esse é o pensamento que nunca para, que nunca medita. Nele não há silêncio do discurso, nele só se vê o ôntico, deixando de lado o ontológico, em outras palavras, só vê o que é do caráter do ente, esquecendo-se, assim, muitas vezes, do ser. Ele é a técnica, o como fazer, é a entificação do ser das coisas e do próprio Dasein.

\section{A subjetividade na Era da Técnica}

Pensando nessa forma calculante de se olhar para o mundo, percebemos que essas tentativas de encarar a natureza como um sistema operativo e calculável de forças não se restringe apenas às ciências ditas naturais. As ciências humanas também se encontram cada vez mais imersas nessa calculicidade. Nesse momento, vislumbramos como a Psicologia depara-se duplamente com os efeitos de vivermos na chamada Era da Técnica.

Por um lado, alguns vieses psicológicos tentam encarar o Dasein como algo padronizável. Busca-se uma compreensão quantitativa baseada em dados ditos concretos e estatísticos, tendo em mente que a Psicologia, como ciência, surge no século XIX, baseando-se em instrumentos e metodologias provenientes das ciências naturais na sua busca de se desvencilhar de uma herança recalcada da Filosofia. A questão do que seria a Psicologia, colocada por um viés epistemológico e histórico, assinala para diversidade da área e a tecnicidade associada à pesquisa quantitativa. Esta se vale de uma concepção do humano, fundada na busca de leis que regem o comportamento, associada às ideias de adaptação, ajuste e natureza humana.

Aliado a esse olhar, encontramos a medicalização, que visaria justamente "corrigir" as chamadas curvas de erros sem querer considerar o singular de cada um. Trabalhando com ideais e aproximando-se do conceito de verdade como Veritas, eles tentam conduzir o psíquico como se ele fosse algo pré-determinado, ou seja, como se ele respondesse ao modo calculante de pensar. Sendo assim, já nesse primeiro ponto, encontramos traços técnicos fortemente presentes em uma forma de se compreender essa área de estudo. Apesar de esse ser apenas um viés em meio à ampla variedade de conceitos e fundamentações nessa área, serve para chamar a atenção de que, até mesmo naquilo o que nos torna mais característicos de quem somos, a técnica busca uma verdade única e irrefutável.

A segunda característica que a Psicologia encontra em nosso horizonte histórico da técnica diz respeito à subjetividade. Essa questão, migrada para a Psicologia na segunda metade do século passado, põe-se justamente em contraponto à noção de natureza humana. Essa posição intenta recuperar a ideia do humano 
como relação e, por isso, sua crítica aos trabalhos baseados em dados quantitativos da Psicologia. É sabido que Heidegger não trabalhou diretamente com esse conceito. No entanto, no momento em que ele afirma que somos, todo o tempo, relação e escolha e, por isso, constituímo-nos em nós mesmos a cada instante, não podemos afirmar que ele não tenha, indiretamente, abordado o tema em questão.

Trazer os pensamentos de Heidegger para a discussão acerca da subjetividade é considerar que o Dasein se encontra jogado nesse horizonte histórico no qual tudo é produção. As demandas técnicas encontram-se tão fortes e delimitadas que são encaradas como a verdade única e irrefutável sobre o mundo e sobre nós. A técnica dita o que devemos acreditar e nós, como meros escravos dela, obedecemos sem nem mesmo questionar o sentido de suas ordens. No momento de nosso nascimento, é o horizonte histórico aquele que nos abre o leque de possibilidades que temos para fazermos nossas escolhas. Isso quer dizer que, apesar de sermos livres, para o entendimento heideggeriano, não o somos completamente. Somos sempre delimitados pelo horizonte histórico no qual nos encontramos.

Um brasileiro, nascido no século XXI, não tem as mesmas escolhas e nem possibilidades do que, por exemplo, um japonês nascido no século XII. Assim, não existiria a possibilidade de um brasileiro do tempo atual transformar-se em um samurai, tornar-se um servo de seu governante a ponto de sair pela rua empunhando uma espada e tendo o direito de matar quem quer que fosse em nome de seu soberano. Do mesmo modo, não caberia a um japonês do século XII tornar-se um técnico em informática ou um programador de jogos de realidade virtual. Por esse motivo, se afirma que o horizonte histórico, de certa forma, sobrepõe-se à ação humana, porque ele é nosso leque de possibilidades, que muda de acordo com a época em questão. Já quanto ao Dasein, independentemente de qual horizonte histórico coabite, cabe a ele realizar escolhas - inclusive a de não escolher, e de como relacionar-se com esse próprio horizonte. Considerando que é esse horizonte que nos determina, ele nos mostra quais possibilidades fazem-se abertas para serem escolhidas, sendo uma problemática central para refletirmos acerca da produção de subjetividade em nossos tempos.

Recordemo-nos de que na era da técnica a verdade é compreendida como veritas, e não como alethéia. O produzir e a utilidade são os objetivos dados como mais óbvios - a ponto de pensarmos a não produção e a inutilidade como perda de tempo e não conseguirmos, com isso, agregar qualquer sentido. Então, o Dasein da era da técnica não tem tempo a perder. Ele precisa de sempre mais. Mais velocidade, mais produção, mais dinheiro, mais inteligência, mais saúde... a lista é infindável - e é preciso dar conta de tudo. Não há tempo para reflexões. Não há tempo para paradas, nem para sustentar mistérios. Por esse motivo, seria possível dizer que ele encontra-se fechado - no sentido de não manter aberturas em relação a si e nem ao mundo. Mas dar conta de tudo é uma tarefa que, quando paramos para refletir, percebemos ser impossível. Não podemos realizar tudo aquilo o que nos é demandado. Não há como sermos, todo o tempo, produtividade, utilidade. E, no instante em que não conseguirmos dar conta desse cálculo, vem o sofrimento, ou seja, o sujeito se torna do-ente. 
De acordo com o sistema de crenças de nosso tempo, é mais fácil acreditarmos que o erro por não conseguir dar conta de tudo só pode ser dos Daseins como produtores - e não da forma que escolhemos nos relacionar com o nosso horizonte histórico. $\mathrm{O}$ número de ditos transtornos mentais, especialmente de ansiedade e depressão - tal qual podemos conferir nas tabelas da World Health Organization - que crescem a cada ano, deveriam ser um indício de que algo estranho está acontecendo. No entanto, em vez de permitirmos esse "estranho" chegar perto de nós e nos mostrar o que precisamos ver, escolhemos, muitas vezes, não nos preocupar e retornar ao impessoal do "isso é assim mesmo". Preferimos nos esconder atrás de remédios que prometem milagres, preferimos nos dopar e procrastinar. Satisfazemo-nos apenas em sobreviver, esquecendo-nos de que estamos vivos, de que somos vivos. $\mathrm{E}$ tudo isso aprendemos desde pequenos, é-nos passado desde a mais tenra idade, o que reforça a sensação de familiaridade com esse modo de vida.

Estamos fechados nessas crenças e parecemos esquecer de que temos a escolha de uma relação mais livre com a técnica. Mas como se conquistaria essa relação mais livre com a técnica? Para Heidegger, por meio da reflexão, de um olhar crítico. Cabe às atividades que despertem a reflexão, como é o caso da psicoterapia, lembrar-nos daquilo o que não podemos esquecer. $\mathrm{E}$ o que necessita urgentemente ser lembrado é justamente a possibilidade dessa forma mais livre, menos fomentadora de transtornos mentais, de nos relacionarmos. Por intermédio desta, temos a possibilidade de escolhermos nosso caminho, afastando-nos do automatismo técnico e apropriando-nos de nós mesmos. Enquanto não encontrarmos espaço para essa reflexão que nos caracteriza como humanos, nos construiremos apenas como se fóssemos uma consequência, uma resposta a nosso meio, como pessoas que não têm direitos sobre suas próprias escolhas. Como, de certa forma, alheios a nós mesmos e ao horizonte histórico em que coexistimos.

\section{Considerações finais}

Vemos, por meio desse trajeto, como a ciência e a técnica entrelaçam-se em um emaranhado de interdependências, já que elas têm uma proveniência comum, advindo de um mesmo acontecimento, ou seja, de um mesmo desvelamento histórico do sentido de ser. Por esse motivo, afirmamos estar vivendo na Era da Técnica, pois esta se faz tão presente e tão intensa que somos levados a pensar que nada mais pode existir no mundo além dela - que ocupa um lugar privilegiado como sendo essencial às nossas necessidades. No momento em que concebemos nosso horizonte histórico como aquele que apresenta o leque de possibilidades dentre as quais o Dasein é livre para escolher, constatamos como a técnica torna-se imprescindível em nossa formação subjetiva.

\section{Referências}

Almeida, L. P. (2007). Pensando a sociedade da informação: reflexões sobre o controle e a homologização no meio digital. Informação \& Sociedade, 17, 83-90.

Barthes, R. (2003). Roland Barthes por Roland Barthes. São Paulo: Estação Liberdade. 
Benjamin, W. (1994). O narrador: considerações sobre a obra de Nikolai Leskov. In W. Benjamin. Magia e técnica, arte e politica: ensaios sobre Literatura e História da Cultura (pp. 197-221). São Paulo: Brasiliense.

Chan, M. (2017) Investing in Treatment for Depression and Anxiety Leads to Fourfold Return. Recuperado de http://www.who.int/mediacentre/news/r eleases/2016/depression-anxietytreatment/en/

Heidegger, M. (1957). O princípio do fundamento. Lisboa: Instituto Piaget.

Heidegger, M. (1959), Serenidade. Lisboa: Instituto Piaget.

Heidegger, M. (1995). Lingua de tradição e língua técnica. Lisboa: Passagens.

Heidegger, M. (2008). Ser e tempo. Petrópolis: Vozes.

Heidegger, M. (2009). Sobre a questão do pensamento. Petrópolis: Vozes.

Heidegger, M. (2010a). A origem da obra de arte. São Paulo: Edições 70.

Heidegger, M. (2010b). Meditação. Petrópolis: Vozes.

Heidegger, M. (2012). A questão da técnica. In M. Heidegger. Ensaios e conferências (pp. 11-38). Petrópolis: Vozes.

Leão, C. (2010). Aprendendo a pensar II (3a ed.). Teresópolis: Daimon Editora.

Novaes, R. S. (2002). A psicoterapia e a questão da técnica. Arquivos Brasileiros de Psicologia,
54(4), 348-362. Rio de Janeiro: Instituto de Psicologia da UFRJ/Ed. Imago.

Novaes, R. S., \& Rodrigues, J. T. (2008). A questão do sujeito e do intimismo em Interpretações fenomenológico-existenciais para o sofrimento psíquico na atualidade. In A. M. Feijoo \& R. N. Sá. (Org.). Interpretações fenomenológicoexistenciais para o sofrimento psíquico na atualidade (pp. 35-54). Rio de Janeiro: Ifen.

Schlick, M. (1980). A causalidade na Física Moderna. In K. Popper, M. Schlick \& R. Carnap. Os pensadores (pp. 10-23). São Paulo: Abril Cultural.

Recebido em: 01/07/2017 Aprovado em: 13/11/2018 